\title{
Idiopathic Upper Extremity Deep Vein Thrombosis with Fatal Pulmonary Embolism: A Case Report
}

\author{
Ranwa BL and Priti $\mathrm{K}^{*}$ \\ Dept of cardiology, JLN hospital, India
}

*Corresponding author: Priti Singhania, Department of Cardiology, JLN hospital, Ajmer, Rajasthan, India, Pin- 305001, Tel: +91-9414000120; Email:

Case Report

Volume 2 Issue 4

Received Date: June 13, 2018

Published Date: July 25, 2018 priti30jan@gmail.com

\begin{abstract}
Idiopathic primary upper extremity deep vein thrombosis is a rare entity. We report case of a young female who presented with fatal pulmonary embolism as sequelae of idiopathic deep vein thrombosis of right upper extremity.

Keywords: Idiopathic Upper Extremity Deep Vein Thrombosis; Pulmonary Embolism
\end{abstract}

Abbrevations: UEDVT: Upper-Extremity Deep Vein Thrombosis; TTE: Transthoracic Echocardiography; TAPSE: Tricuspid Annular Peak Systolic Excursion; CDT: Catheter Directed Thrombolysis.

\section{Introduction}

Upper-extremity deep vein thrombosis (UEDVT) is an increasingly important clinical entity with high potential for morbidity. It is generally secondary to venous catheters, pacemakers, or cancer. Primary UEDVT has been reported in 2 per 100000 patients per year, hence is a rare entity [1]. It is divided into effort thrombosis (the so-called Paget-Schroetter Syndrome) and idiopathic. Here we present a case of a young female who succumbed massive pulmonary embolism following idiopathic upper extremity deep vein thrombosis.

\section{Case Report}

A 35 year old female presented to us with complaints of sudden onset right upper limb swelling for 2 days and breathlessness NYHA class IV for 1 day. On admission, she was conscious, oriented but her general condition was very poor. She was thermodynamically unstable with pulse $=136 / \mathrm{min}, \mathrm{BP}=80 / 60 \mathrm{mmHg}, \mathrm{RR}=46 / \mathrm{min}$, arterial oxygen saturation of $50 \%$ on room air. Jugular venous pulse was elevated $18 \mathrm{~cm}$ above angle of Louis and was non pulsatile. A palpable tender cord like structure was present in right supraclavicular region. All peripheral pulses were palpable with edematous swollen right upper limb. On cardiovascular system examination, left parasternal heave grade III and palpable second heart sound with loud first heart sound and pulmonary component of second heart sound were present. Electrocardiogram showed sinus tachycardia, right axis deviation, $\mathrm{P}$ pulmonale. Chest $\mathrm{X}$ ray showed oligemic lung fields. Coagulation profile and other lab parameters were within normal limits. Venous Doppler showed complete thrombotic occlusion of the right superior vena cava, right subclavian, internal and external jugular veins (Figure 1). 2D transthoracic echocardiography (TTE) revealed dilated right atrium and right ventricle, mild pulmonary arterial hypertension with right ventricular systolic pressure of $40 \mathrm{~mm} \mathrm{Hg}$. Right ventricular systolic function was subnormal with tricuspid annular peak systolic excursion (TAPSE) $12 \mathrm{~mm}$. Left ventricle (LV) function was normal with 'D' shaped LV cavity in systole as well as 


\section{Open Access Journal of Cardiology}

diastole. Parasternal short axis view (PSAX) at aortic valve level showed dilated main pulmonary artery with homogeneous hyperechoeic lesion (13x15mm) obstructing proximal right pulmonary artery (Figure 2). Urgent CT pulmonary angiogram demonstrated hypo intense filling defect $(15 \times 21 \mathrm{~mm})$ in the proximal right pulmonary artery suggestive of thrombus (Figure 3). Patient was advised catheter directed thrombolysis (CDT) or thromboembolectomy. On refusal of consent she was managed with systemic thrombolysis with urokinase $4400 \mathrm{IU} / \mathrm{kg}$ bolus followed by $4400 \mathrm{IU} / \mathrm{kg} / \mathrm{hr}$ continuous infusion with standard anticoagulation and supportive management. Patient continued to deteriorate with worsening of shortness of breath, tachycardia, tachypnea with hemodynamic collapse and death within $3 \mathrm{hrs}$ of admission.
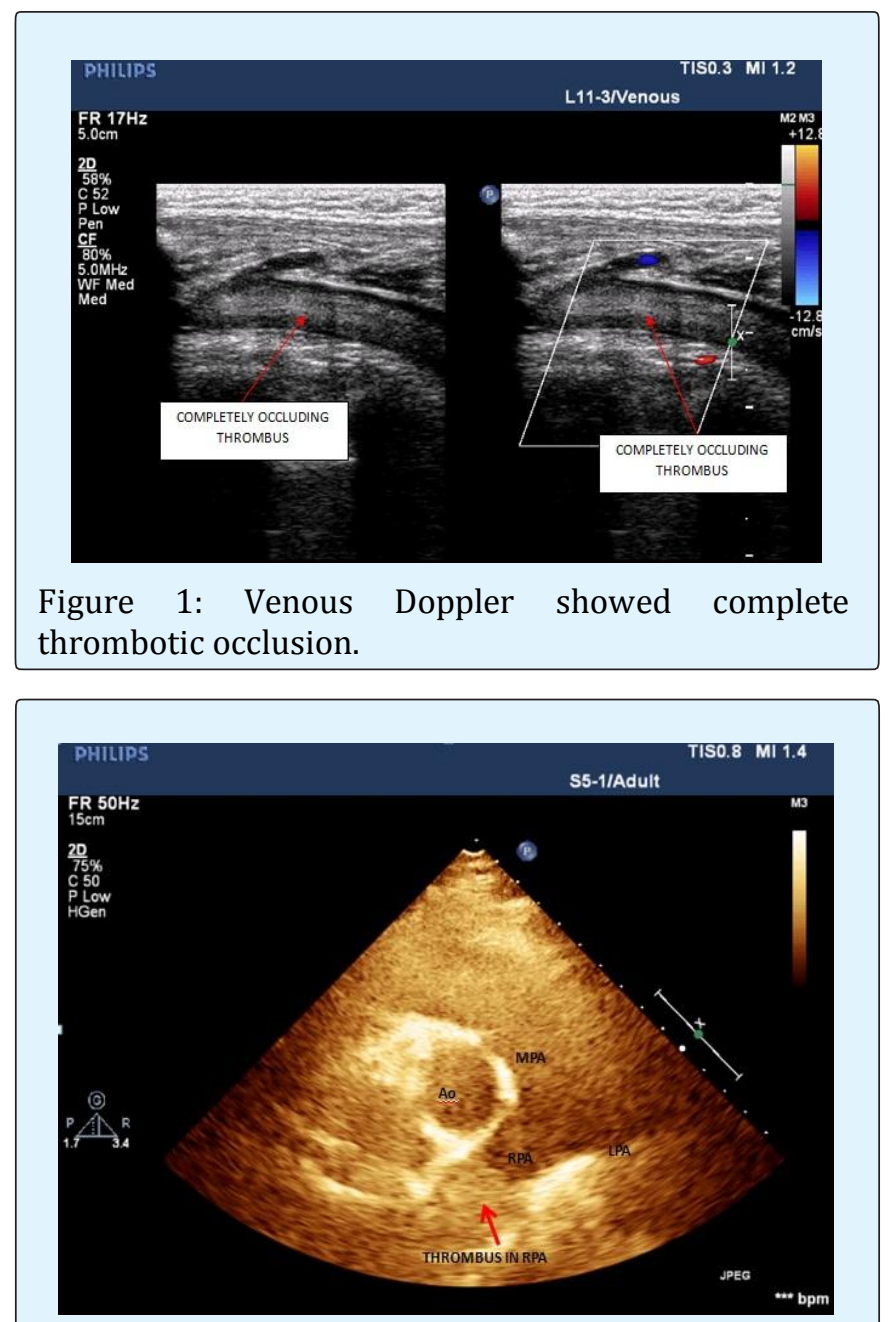

Figure 2: Obstructing proximal right pulmonary artery.

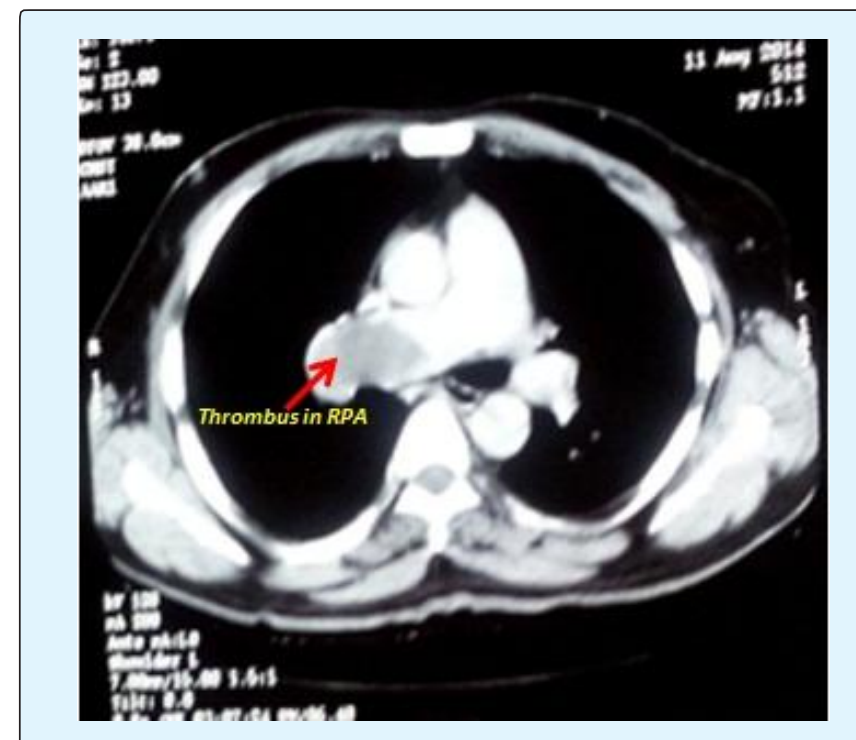

Figure 3: Proximal right pulmonary artery suggestive of thrombus.

\section{Discussion}

Primary upper-extremity deep vein thrombosis is a rare entity. In contrast to patients with Paget-Schroetter Syndrome, patients with idiopathic UEDVT have no known trigger or obvious underlying disease apart from rare cases of occult cancer. In one study, one fourth of patients presenting with idiopathic upper-extremity deep vein thrombosis were diagnosed with cancer (most commonly lung cancer or lymphomas) within 1 year of follow-up [2-4]. Central venous catheters, pacemakers, or cancer may lead to Secondary UEDVT which accounts for most cases of upper-extremity deep vein thrombosis.

Being idiopathic in nature, pathogenesis and treatment of primary UEDVT condition are controversial [5]. The mechanism of injury is widely thought to be associated with repetitive, strenuous upper extremity activities [5]. Symptoms are nonspecific with wide spectrum ranging from entirely asymptomatic to decapacitating illness [5]. Most commonly, however, patient complaints include initial "heaviness" in the affected limb. The differential diagnosis is difficult as these patients typically display compressive signs simulating thoracic outlet syndrome. Pulmonary embolism (PE) is present in up to one third of patients with upper-extremity deep vein thrombosis and is most catastrophic of all the other complications [6]. 


\section{Open Access Journal of Cardiology}

Other complications which include - persistent upperextremity pain and swelling, the superior vena cava (SVC) syndrome, and loss of vascular access, can also be disabling and devastating [7].

Diagnostic modalities include duplex ultrasound, contrast venography and magnetic resonance angiography. Treatment options are limb elevation, graduated compression arm sleeve, anticoagulation (unfractionated heparin/ low molecular weight heparin as "bridge" to warfarin or as monotherapy).Catheterdirected thrombolysis, Suction thrombectomy, angioplasty, vein stenting, Surgical thrombectomy, Thoracic outlet decompression, Surgery, Physical therapy, and Superior vena cava filter. In our case thrombolytic therapy was used to reduce thrombus burden, but a double edge sword due to sequelae of pulmonary embolization, Patient succumbed due to massive pulmonary thromboembolism, the dilemma remains either spontaneous or due to fragile nature of thrombus because of thrombolytic therapy.

\section{Conclusion}

Upper-extremity deep vein thrombosis is a rare venous condition with potential for significant morbidity. Early clinical recognition of the signs and symptoms of UEDVT is necessary to facilitate appropriate treatment to prevent potential complications like pulmonary embolism which have high morbidity and mortality. Early intervention whether surgical or percutaneous should be preferred over pharmacological measures in cases of associated thermodynamically significant pulmonary embolism.

\section{References}

1. Lindblad B, Tengborn L, Bergqvist D (1988) Deep vein thrombosis of the axillary-subclavian veins: epidemiologic data, effects of different types of treatment and late sequelae. Eur J Vasc Surg 2(3): 161-165.

2. Heron E, Lozinguez O, Alhenc-Gelas M, Emmerich J, Fiessinger JN (2000) Hypercoagulable states in primary upper-extremity deep vein thrombosis. Arch Intern Med 160(3): 382-386.

3. Leebeek FW, Stadhouders NA, van Stein D, GómezGarcía EB, Kappers-Klunne MC (2001) Hypercoagulability states in upper-extremity deep venous thrombosis. Am J Hematol 67(1): 15-19.

4. Martinelli I, Cattaneo M, Panzeri D, Taioli E, Mannucci PM (1997) Risk factors for deep venous thrombosis of the upper extremities. Ann Intern Med 126(9): 707711.

5. Azakie A, McElhinney DB, Thompson RW, Raven RB, Messina LM, et al. (1998) Surgical management of subclavian-vein effort thrombosis as a result of thoracic outlet compression. J Vasc Surg 28(5): 777786.

6. Prandoni P, Polistena P, Bernardi E, Cogo A, Casara D (1997) Upper-extremity deep vein thrombosis: risk factors, diagnosis and complications. Arch Intern Med 157(1): 57-62.

7. Becker DM, Philbrick JT, Walker FB (1991) Axillary and subclavian venous thrombosis: prognosis and treatment. Arch Intern Med 151(10): 1934-1943.

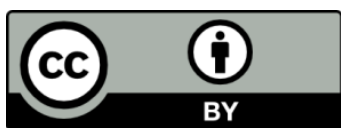

